\title{
ORIGINAL
}

ARTICLES

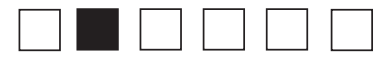

\section{The Scholarly Output of Faculty in Family Medicine Departments}

Winston Liaw, MD, MPH; Stephen Petterson, PhD; Vivian Jiang, MD; Andrew Bazemore, MD, MPH; James Pecsok; Daniel McCorry, MD; Bernard Ewigman, MD, MSPH

BACKGROUND AND OBJECTIVES: While prior efforts have assessed the scope of family medicine research, the methods have differed, and the efforts have not been routinely repeated. The purpose of this analysis was to quantify publications, journals, citations, and funding of US family medicine faculty and identify factors associated with these outcomes.

METHODS: We identified faculty in US departments of family medicine through website searches and performed a cross-sectional study. We included 2015 publications in peer-reviewed journals indexed in Web of Science (a database that aggregates a wide range of catalogs). We calculated descriptive statistics assessing the publications, journals, and citations for family medicine faculty. We conducted bivariate analyses by department region, department size, public/private status, faculty title, and faculty degree.

RESULTS: We identified 6,738 faculty at 134 departments, with $15 \%$ of faculty having any publications. Family medicine faculty published 3,002 times (mean of 2.9 among those with any publications). The mean number of publications was highest for faculty in departments in the West (3.7), in the third quartile for size (3.6), with a professor title (4.0), and with combined MD or DO/PhD degrees (4.3). Faculty published $84 \%$ of the time in non-family medicine journals and were cited 13,548 times. Faculty listed federal funding for over half (52\%) of the times they published.

CONCLUSIONS: Publications from family medicine faculty are not concentrated in family medicine journals and are being referenced by others. These figures are larger than prior estimates and should be tracked over time.

(Fam Med. 2019;51(2):103-11.)

doi: 10.22454/FamMed.2019.536135

$\mathbf{R}$ esearch is critical to family medicine's legitimacy, evolution, and future. ${ }^{1}$ Today, this research enterprise spans the spectrum of health care delivery, from wellness and disease prevention to management of multiple chronic conditions and social determinants of health. The knowledge generated affects change at the individual, beyond academic walls, broadening its impact. Practice-based research networks (PBRNs) reach $15 \%$ of the US population, and numerous family medicine researchers engage communities through participatory research. ${ }^{6}$

Previous attempts to measure family medicine research output have alluded to the challenge of capturing its scope and highlighted others. ${ }^{7-9,4,10}$ For example, family medicine scholars often collaborate with experts in other fields (eg, psychology, social work) and publish in nonclinical fields (eg, information technology) while experts in other disciplines and specialties also publish in leading family medicine journals. ${ }^{4,8}$ Prior work has used a wide range of inclusion criteria, databases, and methods to capture research productivity in family medicine. ${ }^{7-9,4,10}$ Though heterogeneous, most have pointed toward a general increase in family medicine scholarly production over time and noted that the

From the Robert Graham Center, Policy Studies in Family Medicine and Primary Care (Drs Liaw, Petterson, and Bazemore); University of Houston College of Medicine, Department of Health Systems and Population Health Sciences (Dr Liaw); Virginia Commonwealth University Department of Family Medicine (Dr Jiang); Eastern Virginia Medical School, Norfolk, VA (Mr Pecsok); McLeod Family Medicine Residency Program, Florence, SC (Dr McCorry); and University of Chicago and NorthShore University HealthSystem, Department of Family Medicine (Dr Ewigman). 
field lacks a well-accepted methodology for identifying its works. One prior assessment found that most family medicine articles were published without external funding. ${ }^{10}$ Within this context, we sought to quantify the publications by faculty in departments of family medicine in 2015 based on a bibliometric analysis, identify the journals in which they were published, determine the percentage that were original research articles, quantify the impact of these publications based on citations in 2017, identify the funders supporting these publications, and identify factors associated with publications, citations, and funding.

\section{Methods}

In this descriptive, bibliometric analysis, we identified faculty within departments of family medicine, then determined the scholarly publications they produced in 2015 .

\section{Data Sources}

We used department websites to obtain the names, academic degrees, and titles of faculty. To identify scholarly publications and citations, we used Web of Science (WOS), a subscription-based database which covers biomedical, social science, arts, and humanities journals. Its science collection contains 33,000 journals and is broader than that of PubMed. ${ }^{11,12}$ In addition to journal articles, WOS also covers conference proceedings and books. To identify US departments of family medicine, we used a database from the Association of Departments of Family Medicine (ADFM), that includes accredited allopathic and osteopathic medical schools with family medicine departments. To determine additional characteristics of family medicine departments, we used data from the Association of American Medical Colleges (AAMC) website. ${ }^{13}$

We assessed the accuracy of these data sources in a related, yet-to-bepublished study conducted in partnership with the ADFM. In that study, we asked chairs from 13 departments of family medicine to list the faculty in their department who met criteria outlined below. Of the unique names identified through websites and reported by departments, website searches identified $87 \% .{ }^{14}$ Chairs also reported publications from their faculty in 2015, against which we compared the WOS-based method presented here and another method using the PubMed author affiliation field. Across all publications identified from these three methods, the WOS approach identified 58.6\%. ${ }^{14}$

\section{Variables}

In the spring of 2017, we used Google internet searches to identify webpages for each included department. Within each department webpage, we recorded faculty member names, academic degrees, and titles. Because we were interested in the output of faculty responsible for scholarship within the department, we limited the academic appointments to and categorized appointments as assistant professor, associate professor, professor, clinical assistant professor, clinical associate professor, clinical professor, and chair, or their respective equivalent ranks. Therefore, we excluded those with titles such as adjunct faculty, clinician educator, and instructor. We included all divisions within departments, including sports medicine, geriatrics, population health, occupational medicine, and public health.

WOS categorizes publications into 43 groups, from which we developed two outcomes: all publications and original research articles only. For "all publications," we included articles, books, book chapters, book reviews, early access articles, editorial material, fiction, film reviews, items about individuals, letters, poetry, proceedings papers (including conference proceedings), and reviews. The second outcome, "original research articles only," was defined by WOS as reports of research on original work. For both outcomes, we excluded the remaining WOS categories, which included art exhibit reviews, dance performance reviews, corrections, and reprints. We identified the top 10 family medicine journals by summing the number of times faculty published in each journal and identifying the journals with the 10 highest sums. Additionally, we calculated the number of times faculty published in four of the highest impact journals (Journal of the American Medical Association, British Medical Journal, New England Journal of Medicine, and Lancet). To assess productivity, we calculated the number of times each faculty published and unique publications for the specialty as a whole.

We matched faculty names and institutions with authors and their affiliations for publications in WOS that were published between January 1, 2015 and December 31, 2015. In addition to name, the WOS fields we used for matching included author country, state, city, department name, and institution. We included all of the publications, which matched name, department, and institution. For those publications that only matched institution (eg, did not include family medicine), state, or country, we reviewed the publications and names individually, excluding partial matches where the faculty could not be directly linked to the author affiliation institution. For example, we excluded publications that matched names if the author affiliation institution was the Cleveland Clinic but the faculty's appointment was with Case Western Reserve University.

To identify factors associated with our outcomes, we assessed individual faculty and department characteristics. We grouped departments into four geographic regions (Midwest, Northeast, South, and West), excluding the medical schools in Puerto Rico. We used information from the AAMC and American Association of Colleges of Osteopathic Medicine to determine whether the institutions were public or private. ${ }^{13,15} \mathrm{We}$ also grouped departments in size quartiles based on the number of faculty. We used four categories for academic degrees: (1) $\mathrm{MD}$ or $\mathrm{DO}$, (2) $\mathrm{PhD},(3)$ 
combined $\mathrm{MD}$ or $\mathrm{DO}$ and $\mathrm{PhD}$, and (4) other (eg, pharmacists, dietitians, and social workers).

We assessed funding by using the information provided within the WOS metadata and grouped sources into four categories (university, federal, other, and none). We considered a publication to be funded by university sources if the authors reported internal funding from a university. Federal funding included funding from US agencies, including the National Institutes of Health, Veterans Administration, Agency for Healthcare Research and Quality, and Patient-Centered Outcomes Research Institute. Sources that could not be placed in the first two categories were placed in the other group, which included foundations, state agencies, pharmaceutical companies, and international funders. The remaining publications were listed as having no external funding. Papers could receive funding from multiple sources.

\section{Analytic Plan}

We conducted univariate and bivariate analyses to capture publications (all publications and original research articles only), journals, citations, and funding. In bivariate analyses, we assessed these outcomes for region, department size, public/private status, faculty academic degrees, and faculty titles.

The American Academy of Family Physicians Institutional Review Board approved this protocol.

\section{Results}

We included 134 schools and 6,736 faculty in our analysis (Table 1). Nearly $81 \%$ of these were MDs or DOs only while $10 \%$ were $\mathrm{PhDs}$ only. Thirty-six percent were assistant professors, while this figure was $14 \%$ and $13 \%$ for associate professors and professors, respectively.

With respect to the number of times faculty published in specific journals, half of the top 10 journals are family medicine-centric (Table 2). The remainder are related to academic medicine, public health, primary care, and occupational and environmental medicine. Overall, family medicine faculty published $24 \%$ of the time in these top 10 journals and $16 \%$ of the time in the five family medicine-centric journals. In total, faculty published in

Table 1: Faculty Degrees, by Region, Department Size, and Faculty Title

\begin{tabular}{|l|c|c|c|c|c|c|c|c|c|c|}
\hline \multicolumn{2}{|c|}{} & \multicolumn{2}{c|}{ MD/DO Only } & \multicolumn{2}{c|}{ PhD Only } & \multicolumn{2}{c|}{$\begin{array}{c}\text { MD/DO } \\
\text { \& PhD }\end{array}$} & \multicolumn{2}{c|}{ Other Degree } \\
\hline & Schools (n) & Faculty (n) & $\mathbf{n}$ & $\%$ & $\mathbf{n}$ & $\%$ & $\mathbf{n}$ & $\%$ & $\mathbf{n}$ & $\%$ \\
\hline All schools & 134 & 6,738 & 5,434 & 80.6 & 657 & 9.8 & 123 & 1.8 & 524 & 7.8 \\
\hline \multicolumn{1}{|c|}{ Region } & & & & & & & & & & \\
\hline Midwest & 39 & 2,294 & 1,824 & 79.5 & 201 & 8.8 & 55 & 2.4 & 214 & 9.3 \\
\hline Northeast & 26 & 1,744 & 1,469 & 84.2 & 153 & 8.8 & 20 & 1.1 & 102 & 5.8 \\
\hline South & 51 & 1,559 & 1,253 & 80.4 & 152 & 9.7 & 26 & 1.7 & 128 & 8.2 \\
\hline West & 18 & 1,141 & 888 & 77.8 & 151 & 13.2 & 22 & 1.9 & 80 & 7.0 \\
\hline \multicolumn{1}{|c|}{ Department Size } & & & & & & & & & & \\
\hline $2-44$ & 81 & 1,776 & 1,400 & 78.8 & 223 & 12.6 & 36 & 2.0 & 117 & 6.6 \\
\hline $45-89$ & 29 & 1,690 & 1,406 & 83.2 & 151 & 8.9 & 27 & 1.6 & 106 & 6.3 \\
\hline $94-128$ & 15 & 1,554 & 1,157 & 74.5 & 149 & 9.6 & 29 & 1.9 & 219 & 14.1 \\
\hline 131-287 & 9 & 1,718 & 1,471 & 85.6 & 134 & 7.8 & 31 & 1.8 & 82 & 4.8 \\
\hline \multicolumn{1}{|c|}{ School Type } & & & & & & & & & \\
\hline Private & 43 & 2,423 & 2,029 & 83.7 & 179 & 7.4 & 47 & 1.9 & 168 & 6.9 \\
\hline Public & 91 & 4,315 & 3,405 & 78.9 & 478 & 11.1 & 76 & 1.8 & 356 & 8.3 \\
\hline \multicolumn{1}{|c|}{ Faculty Title } & & & & & & & & & & \\
\hline Assistant professor & & 2,426 & 1,887 & 77.8 & 233 & 9.6 & 35 & 1.4 & 271 & 11.2 \\
\hline Associate professor & & 954 & 688 & 72.1 & 163 & 17.1 & 22 & 2.3 & 81 & 8.5 \\
\hline Professor & & 862 & 562 & 65.2 & 195 & 22.6 & 37 & 4.3 & 68 & 7.9 \\
\hline Chair & & 135 & 128 & 94.8 & 0 & 0.0 & 4 & 3.0 & 3 & 2.2 \\
\hline Clinical assistant professor & & 1,944 & 1,808 & 93.0 & 36 & 1.9 & 19 & 1.0 & 81 & 4.2 \\
\hline Clinical associate professor & & 274 & 237 & 86.5 & 18 & 6.6 & 4 & 1.5 & 15 & 5.5 \\
\hline Clinical professor & & 143 & 124 & 86.7 & 12 & 8.4 & 2 & 1.4 & 5 & 3.5 \\
\hline
\end{tabular}

Faculty names, titles, and degrees were obtained through web searches. 
Table 2: Top 10 and High-Impact Journals With Family Medicine Faculty Publications

\begin{tabular}{|c|c|c|c|}
\hline Journal & Impact Factor & Times Published (n) & $\%$ \\
\hline \multicolumn{4}{|l|}{ Top 10 Journals } \\
\hline Journal of the American Board of Family Medicine & 2.0 & 146 & 4.9 \\
\hline Family Medicine & 1.2 & 146 & 4.9 \\
\hline American Family Physician & 1.8 & 92 & 3.1 \\
\hline Journal of Family Practice & 0.7 & 60 & 2.0 \\
\hline Annals of Family Medicine & 4.9 & 50 & 1.7 \\
\hline Academic Medicine & 5.3 & 48 & 1.6 \\
\hline American Journal of Public Health & 3.9 & 47 & 1.6 \\
\hline Journal of General Internal Medicine & 3.7 & 47 & 1.6 \\
\hline Plos One & 2.8 & 44 & 1.5 \\
\hline Journal of Occupational and Environmental Medicine & 1.9 & 35 & 1.2 \\
\hline Top 10 Total & & 715 & 23.8 \\
\hline \multicolumn{4}{|l|}{ High-Impact Journals } \\
\hline Journal of the American Medical Association & 44.4 & 21 & 0.7 \\
\hline British Medical Journal & 20.8 & 7 & 0.2 \\
\hline New England Journal of Medicine & 72.4 & 5 & 0.2 \\
\hline Lancet & 47.8 & 1 & 0.0 \\
\hline High Impact Total & & 34 & 1.1 \\
\hline
\end{tabular}

Impact factors are from the 2016 InCites Journal Citation Report. The percentage denominator is the total times published across all faculty. The times published reflects the times faculty published an item within the all publications outcome $(3,002)$ and is not restricted to original research articles only.

856 unique journals, or in $2.6 \%$ of the journals available through WOS.

Using all publications as the outcome, family medicine faculty published over 3,000 times in 2015 (Table 3). These correspond to 2,313 unique publications due to multiple family medicine authors contributing to the same publications. Among those publishing, the mean number of times that faculty published was 2.9. The mean number of publications was higher for faculty in departments in the West, in the third quartile for size, with professor titles, and with combined MD or DO and $\mathrm{PhD}$ degrees. Assistant professors, associate professors, professors, and chairs accounted for $93 \%$ of all of the times that faculty published. Thus, despite comprising $35 \%$ of all faculty, faculty with clinical appointments (clinical assistant, clinical associate, and clinical professors) accounted for only $7 \%$ of all the times faculty published. Fifteen percent of all faculty had any publications. Of all of the times that faculty published, $83 \%$ were original research articles.

By 2017 , faculty were cited 13,548 times, or a mean of 4.5 times cited per faculty (Table 4). These correspond to 10,140 unique citations, or a mean of 5.9 citations per unique article. Over $90 \%$ of publications had at least one citation. Professors had the highest mean citations per faculty and accounted for $55 \%$ of all citations. In contrast, clinical professors had the lowest mean citations. Of all the times that faculty published, two-thirds reported external funding (Table 5), and over half reported federal funding. The percentage of faculty reporting federal funding was highest for those in departments in the West, in the largest quartile for department size, private institutions, professors, and $\mathrm{PhDs}$ only.

\section{Discussion}

In 2015, family medicine faculty published over 3,000 times and were cited over 13,500 times 2 years after publication. These correspond to 2,313 unique publications and 10,140 unique citations. Using different methods and including articles that systematically gathered and analyzed data, Pathman et al identified 790 articles published by family medicine scholars in 2003, and at the time, heralded the contribution as "larger and more productive than generally recognized." ${ }^{4}$ While a portion of this growth may be attributable to an increase in the number of journals, the annualized growth rate in family medicine production (9.4\%) still outpaces the annualized growth rate in records within PubMed $(5.6 \%) .{ }^{16}$ In this study, two-thirds of faculty publications reported federal funding, in contrast to a 1992 study demonstrating that the majority were completed without external funding. The number of faculty we calculated $(6,738)$ is comparable to a previous estimate calculated by Weaver $(8,433) .{ }^{17}$ Weaver's figure is likely higher due to the inclusion of 
Table 3: All Publications and Original Research Articles by Region, Department Size, Faculty Title, and Faculty Degree

\begin{tabular}{|c|c|c|c|c|c|c|c|c|c|c|c|c|c|c|c|}
\hline & \multirow[b]{3}{*}{$\begin{array}{l}\frac{7}{5} \\
\text { एँ } \\
\text { एँ }\end{array}$} & \multicolumn{7}{|c|}{ All Publications } & \multicolumn{7}{|c|}{ Original Research Articles } \\
\hline & & \multirow{2}{*}{ 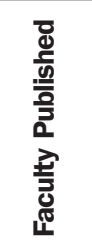 } & \multirow[b]{2}{*}{ o } & \multirow{2}{*}{ 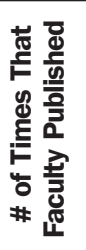 } & \multicolumn{2}{|c|}{ Mean } & \multirow[b]{2}{*}{ 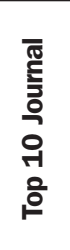 } & \multirow[b]{2}{*}{ o } & \multirow{2}{*}{ 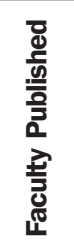 } & \multirow[b]{2}{*}{ o } & \multirow{2}{*}{ 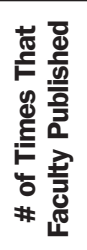 } & \multicolumn{2}{|c|}{ Mean } & \multirow[b]{2}{*}{ 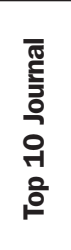 } & \multirow[b]{2}{*}{ o } \\
\hline & & & & & 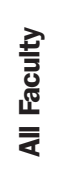 & 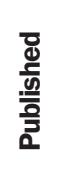 & & & & & & 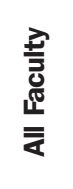 & 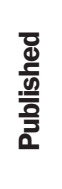 & & \\
\hline All schools & 6,738 & 1,042 & 15.5 & 3002 & 0.5 & 2.9 & 677 & 22.6 & 851 & 12.6 & 2,499 & 0.4 & 2.9 & 501 & 20.0 \\
\hline \multicolumn{16}{|l|}{ Region } \\
\hline Midwest & 2,294 & 272 & 11.9 & 669 & 0.3 & 2.5 & 138 & 20.6 & 218 & 9.5 & 549 & 0.2 & 2.5 & 99 & 18.0 \\
\hline Northeast & 1,744 & 243 & 13.9 & 701 & 0.4 & 2.9 & 106 & 15.1 & 198 & 11.4 & 578 & 0.3 & 2.9 & 80 & 13.8 \\
\hline South & 1,559 & 262 & 16.8 & 654 & 0.4 & 2.5 & 201 & 30.7 & 216 & 13.9 & 541 & 0.4 & 2.5 & 148 & 27.4 \\
\hline West & 1,141 & 265 & 23.2 & 978 & 0.9 & 3.7 & 232 & 23.7 & 219 & 19.2 & 831 & 0.7 & 3.8 & 174 & 20.9 \\
\hline \multicolumn{16}{|l|}{$\begin{array}{c}\text { Department } \\
\text { Size }\end{array}$} \\
\hline $2-44$ & 1,776 & 301 & 16.9 & 734 & 0.4 & 2.4 & 225 & 30.7 & 255 & 14.4 & 641 & 0.4 & 2.5 & 181 & 28.2 \\
\hline $45-89$ & 1,690 & 299 & 17.7 & 809 & 0.5 & 2.7 & 209 & 25.8 & 246 & 14.6 & 665 & 0.4 & 2.7 & 153 & 23.0 \\
\hline 94-128 & 1,554 & 244 & 15.7 & 875 & 0.6 & 3.6 & 161 & 18.4 & 196 & 12.6 & 718 & 0.5 & 3.7 & 109 & 15.2 \\
\hline $131-287$ & 1,718 & 198 & 11.5 & 584 & 0.3 & 3.0 & 82 & 14.0 & 154 & 9.0 & 475 & 0.3 & 3.1 & 58 & 12.2 \\
\hline \multicolumn{16}{|l|}{ School Type } \\
\hline Private & 2,423 & 293 & 12.1 & 838 & 0.4 & 2.9 & 140 & 16.7 & 237 & 9.8 & 696 & 0.3 & 2.9 & 101 & 14.5 \\
\hline Public & 4,315 & 749 & 17.4 & 2164 & 0.5 & 2.9 & 537 & 24.8 & 614 & 14.2 & 1,803 & 0.4 & 2.9 & 400 & 22.2 \\
\hline \multicolumn{16}{|l|}{ Faculty Title } \\
\hline $\begin{array}{l}\text { Assistant } \\
\text { professor }\end{array}$ & 2,426 & 285 & 11.7 & 578 & 0.2 & 2.0 & 165 & 28.5 & 242 & 10.0 & 498 & 0.2 & 2.1 & 129 & 25.9 \\
\hline $\begin{array}{l}\text { Associate } \\
\text { professor }\end{array}$ & 954 & 237 & 24.8 & 615 & 0.6 & 2.6 & 142 & 23.1 & 193 & 20.2 & 512 & 0.5 & 2.7 & 112 & 21.9 \\
\hline Professor & 862 & 372 & 43.2 & 1475 & 1.7 & 4.0 & 270 & 18.3 & 304 & 35.3 & 1,237 & 1.4 & 4.1 & 199 & 16.1 \\
\hline Chair & 135 & 41 & 30.4 & 122 & 0.9 & 3.0 & 57 & 46.7 & 34 & 25.2 & 95 & 0.7 & 2.8 & 42 & 44.2 \\
\hline $\begin{array}{l}\text { Clinical } \\
\text { assistant } \\
\text { professor }\end{array}$ & 1,944 & 44 & 2.3 & 92 & 0.1 & 2.1 & 12 & 13.0 & 33 & 1.7 & 73 & 0.04 & 2.2 & 6 & 8.2 \\
\hline $\begin{array}{l}\text { Clinical } \\
\text { associate } \\
\text { professor }\end{array}$ & 274 & 32 & 11.7 & 74 & 0.3 & 2.3 & 16 & 21.6 & 22 & 8.0 & 50 & 0.2 & 2.3 & 6 & 12.0 \\
\hline $\begin{array}{l}\text { Clinical } \\
\text { professor }\end{array}$ & 143 & 31 & 21.7 & 46 & 0.3 & 1.5 & 15 & 32.6 & 23 & 16.1 & 34 & 0.2 & 1.5 & 7 & 20.6 \\
\hline \multicolumn{16}{|l|}{$\begin{array}{l}\text { Faculty } \\
\text { degree }\end{array}$} \\
\hline $\begin{array}{l}\text { MD or DO } \\
\text { only }\end{array}$ & 5,434 & 611 & 11.2 & 1471 & 0.3 & 2.4 & 435 & 29.6 & 470 & 8.6 & 1,146 & 0.2 & 2.4 & 288 & 25.1 \\
\hline PhD only & 657 & 301 & 45.8 & 1122 & 1.7 & 3.7 & 164 & 14.6 & 278 & 42.3 & 1,028 & 1.6 & 3.7 & 151 & 14.7 \\
\hline $\begin{array}{l}\mathrm{MD} / \mathrm{DO} \& \\
\mathrm{PhD}\end{array}$ & 123 & 42 & 34.1 & 179 & 1.5 & 4.3 & 35 & 19.6 & 33 & 26.8 & 141 & 1.2 & 4.3 & 32 & 22.7 \\
\hline Other & 524 & 88 & 16.8 & 230 & 0.4 & 2.6 & 43 & 18.7 & 70 & 13.4 & 184 & 0.4 & 2.6 & 30 & 16.3 \\
\hline
\end{tabular}


Table 4: Citations, by Region, Department Size, Faculty Title, and Faculty Degree

\begin{tabular}{|c|c|c|c|c|c|}
\hline & $\begin{array}{l}\text { \# of Times That } \\
\text { Faculty Published }\end{array}$ & $\begin{array}{l}\text { \# of Times That } \\
\text { Faculty Were Cited }\end{array}$ & Mean & Any Citation (n) & $\%$ \\
\hline All schools & 3,002 & 13,548 & 4.5 & 2,809 & 93.6 \\
\hline \multicolumn{6}{|l|}{ Region } \\
\hline Midwest & 669 & 2,560 & 3.8 & 602 & 90.0 \\
\hline Northeast & 701 & 3,868 & 5.5 & 661 & 94.3 \\
\hline South & 654 & 2,175 & 3.3 & 611 & 93.4 \\
\hline West & 978 & 4,945 & 5.1 & 935 & 95.6 \\
\hline \multicolumn{6}{|c|}{ Department Size } \\
\hline $2-44$ & 734 & 2,889 & 3.9 & 685 & 93.3 \\
\hline $45-89$ & 809 & 3,119 & 3.9 & 756 & 93.4 \\
\hline $94-128$ & 875 & 4,169 & 4.8 & 829 & 94.7 \\
\hline $131-287$ & 584 & 3,371 & 5.8 & 539 & 92.3 \\
\hline \multicolumn{6}{|l|}{ School Type } \\
\hline Private & 838 & 4,342 & 5.2 & 789 & 94.2 \\
\hline Public & 2,164 & 9,206 & 4.3 & 2,020 & 93.3 \\
\hline \multicolumn{6}{|l|}{ Faculty Title } \\
\hline Assistant professor & 578 & 2,191 & 3.8 & 513 & 88.8 \\
\hline Associate professor & 615 & 2,510 & 4.1 & 574 & 93.3 \\
\hline Professor & 1,475 & 7,464 & 5.1 & 1,428 & 96.8 \\
\hline Chair & 122 & 600 & 4.9 & 115 & 94.3 \\
\hline $\begin{array}{l}\text { Clinical assistant } \\
\text { Professor }\end{array}$ & 92 & 360 & 3.9 & 80 & 87.0 \\
\hline $\begin{array}{l}\text { Clinical associate } \\
\text { Professor }\end{array}$ & 74 & 301 & 4.1 & 67 & 90.5 \\
\hline Clinical professor & 46 & 122 & 2.7 & 32 & 69.6 \\
\hline \multicolumn{6}{|l|}{ Faculty Degree } \\
\hline $\mathrm{MD}$ or DO only & 1,471 & 6,353 & 4.3 & 1,352 & 91.9 \\
\hline $\mathrm{PhD}$ only & 1,122 & 5,298 & 4.7 & 1,075 & 95.8 \\
\hline MD/DO \& PhD & 179 & 770 & 4.3 & 173 & 96.6 \\
\hline Other & 230 & 1,127 & 4.9 & 209 & 90.9 \\
\hline
\end{tabular}

The times published reflects the times faculty published an item within the all publications outcome and is not restricted to original articles only.

community-based family medicine residency faculty who do not have formal academic titles such as the ones we used as inclusion criteria.

Our results provide insights into the scope of family medicine research. Family medicine faculty published in 856 unique journals, the vast majority (84\%) of which were non-family medicine journals. In his declaration of general practice as an academic discipline, Ian McWhinney foresaw the opportunity for learning in the "twilight zones" where disciplines meet and viewed generalism as the intersection of medicine, psychology, and sociology. ${ }^{1}$ By spanning domains and journals, these results support McWhinney's vision of the generalist research enterprise.

Several factors could account for the increase in publications over time. To reduce widespread gaps in quality, stakeholders implemented strategies to systematically improve care..$^{18}$ Practices, particularly those applying for patient centered medical home certification, embraced quality improvement principles. ${ }^{19} \mathrm{On}$ the education side, specialty boards transitioned to maintenance of certification and encouraged continuous learning. ${ }^{20}$ Academic health centers sought to integrate delivery and research silos by applying principles of learning health care systems. ${ }^{21}$ Research and quality improvement were built into residency milestones. ${ }^{22}$ The Accreditation Council for Graduate Medical Education mandated that faculty must engage in scholarship that includes publication and presentations. ${ }^{23}$ All of these movements pushed faculty toward evaluating whether their care 
Table 5: Funding* by Region, Department Size, Faculty Title, and Faculty Degree

\begin{tabular}{|c|c|c|c|c|c|c|c|c|c|}
\hline & \multirow{2}{*}{$\begin{array}{l}\text { \# of Times That } \\
\text { Faculty Published }\end{array}$} & \multicolumn{2}{|c|}{ University } & \multicolumn{2}{|c|}{ Federal } & \multicolumn{2}{|c|}{ Other } & \multicolumn{2}{|c|}{ No External Funding } \\
\hline & & $n$ & $\%$ & $\mathbf{n}$ & $\%$ & $\mathbf{n}$ & $\%$ & $n$ & $\%$ \\
\hline All schools & 3,002 & 304 & 10.1 & 1,565 & 52.1 & 366 & 12.2 & 950 & 31.6 \\
\hline \multicolumn{10}{|l|}{ Region } \\
\hline Midwest & 669 & 81 & 2.7 & 324 & 48.4 & 63 & 9.4 & 252 & 37.7 \\
\hline Northeast & 701 & 60 & 2.0 & 378 & 53.9 & 106 & 15.1 & 194 & 27.7 \\
\hline South & 654 & 64 & 2.1 & 274 & 41.9 & 77 & 11.8 & 264 & 40.4 \\
\hline West & 978 & 99 & 3.3 & 589 & 60.2 & 120 & 12.3 & 240 & 24.5 \\
\hline \multicolumn{10}{|l|}{ Department Size } \\
\hline $2-44$ & 734 & 74 & 2.5 & 352 & 48.0 & 66 & 9.0 & 285 & 38.8 \\
\hline $45-89$ & 809 & 101 & 3.4 & 393 & 48.6 & 123 & 15.2 & 244 & 30.2 \\
\hline $94-128$ & 875 & 78 & 2.6 & 474 & 54.2 & 114 & 13.0 & 261 & 29.8 \\
\hline $131-287$ & 584 & 51 & 1.7 & 346 & 59.2 & 63 & 10.8 & 160 & 27.4 \\
\hline \multicolumn{10}{|l|}{ School Type } \\
\hline Private & 838 & 64 & 2.1 & 469 & 56.0 & 126 & 15.0 & 219 & 26.1 \\
\hline Public & 2,164 & 240 & 8.0 & 1,096 & 50.6 & 240 & 11.1 & 731 & 33.8 \\
\hline \multicolumn{10}{|l|}{ Faculty Title } \\
\hline Assistant professor & 578 & 69 & 2.3 & 294 & 50.9 & 64 & 11.1 & 189 & 32.7 \\
\hline Associate professor & 615 & 56 & 1.9 & 285 & 46.3 & 71 & 11.5 & 231 & 37.6 \\
\hline Professor & 1,475 & 152 & 5.1 & 851 & 57.7 & 194 & 13.2 & 379 & 25.7 \\
\hline Chair & 122 & 16 & 0.5 & 60 & 49.2 & 7 & 5.7 & 51 & 41.8 \\
\hline $\begin{array}{l}\text { Clinical assistant } \\
\text { professor }\end{array}$ & 92 & 3 & 0.1 & 47 & 51.1 & 13 & 14.1 & 31 & 33.7 \\
\hline $\begin{array}{l}\text { Clinical associate } \\
\text { professor }\end{array}$ & 74 & 6 & 0.2 & 16 & 21.6 & 11 & 14.9 & 42 & 56.8 \\
\hline Clinical professor & 46 & 2 & 0.1 & 12 & 26.1 & 6 & 13.0 & 27 & 58.7 \\
\hline \multicolumn{10}{|l|}{ Faculty Degree } \\
\hline MD or DO only & 1,471 & 141 & 4.7 & 653 & 44.4 & 185 & 12.6 & 567 & 38.5 \\
\hline $\mathrm{PhD}$ only & 1,122 & 124 & 4.1 & 711 & 63.4 & 126 & 11.2 & 239 & 21.3 \\
\hline $\mathrm{MD} / \mathrm{DO} \& \mathrm{PhD}$ & 179 & 21 & 0.7 & 91 & 50.8 & 28 & 15.6 & 55 & 30.7 \\
\hline Other & 230 & 18 & 0.6 & 110 & 47.8 & 27 & 11.7 & 89 & 38.7 \\
\hline
\end{tabular}

* Funding is that listed on individual faculty publications. Publications can have multiple sources of funding.

The times published reflects the times faculty published an item within the all publications outcome and is not restricted to original articles only.

improves outcomes and may have contributed to the growth in publications. Simultaneously, the available outlets for these manuscripts has grown. With the internet reducing barriers to entry, the number of journals has steadily increased over time. ${ }^{16}$

These data may prove useful for guiding promotion decisions and providing benchmarks. For example, they can be updated over time to quantify the return on investments in research infrastructure. One such investment is Family Medicine for America's Health (FMAHealth), a national initiative to integrate family medicine organizations to chart the future of the discipline. ${ }^{24}$ In addition to launching this effort, the FMAHealth Research Tactic Team sought to understand the state of family medicine research and stimulate conversations about how to bolster its research enterprise. Using the data presented in this work, we hope to identify and disseminate lessons from highly productive departments so that all departments can learn from effective strategies. Further, our data highlight opportunities for improvement as only $15 \%$ of faculty published anything. As clinical faculty appointments expand, these trends will need to be monitored. ${ }^{25}$ Nonpublishing faculty likely have research questions and insights that need to be shared with the broader academic community. Understanding the characteristics of nonpublishing faculty and their barriers to scholarship will be critical to increasing 
participation. It remains to be seen whether the aforementioned initiatives to enhance scholarship will lead to broader participation. Finally, these figures should be reproduced and tracked at regular intervals. For educators and workforce planners, the annual publication that updates the number of available and filled family medicine residency slots provides important guidance, allowing stakeholders to track and respond to trends..$^{26} \mathrm{~A}$ similar effort for family medicine faculty, publications, citations, and funding could prove critical to building on the successes documented here.

There are numerous limitations that should be considered when assessing our results. First, given our desire to develop a reproducible method, we only captured scholarly publications produced by a subset of faculty. However, we contend that these were the faculty that were most likely to publish. Second, we limited our publications to those listed in WOS. Therefore, we missed articles that were in nonindexed journals and scholarly publications not included in WOS. These presentations, curricula, and articles have tremendous value to the discipline and are not captured by this method. Third, the accuracy of faculty lists on websites is limited by the frequency with which those websites are updated. We assessed faculty names and appointments in 2017 while the actual roster of faculty may have differed in 2015 . Fourth, since we lack a unique identifier that spans faculty rosters and WOS publications, we matched a subset of publications manually. As noted in the methods, we used names and the author affiliation institutions to match authors. Imprecision in names (eg, the use of a nickname when publishing) and affiliations (eg, identifying only a hospital rather than an institution) limited the certainty of some matches. Unfortunately, it is possible that we missed publications of faculty who listed nonuniversity affiliations and that we included publications of faculty not in departments of family medicine. While an approach that combined multiple methods and allowed faculty to add, modify, or remove publications from this list would be an improvement, this approach would be more resource intensive and could introduce bias if only a subset of faculty participated in verification. Fifth, we did not attempt to evaluate the quality of publications by assessing the study designs or the importance of the findings. Finally, we omitted a wide range of family medicine scholars not primarily affiliated with departments of family medicine, including those working at the American Academy of Family Physicians, American Board of Family Medicine, and health systems like Kaiser and the Veterans Administration. Taken together, these limitations strongly suggest that our figures are conservative. As previously mentioned, in a companion ADFM study, we found that this WOS approach discovered only $58.6 \%$ of the publications identified across three methods. Extrapolating from this figure, it is possible that the method we used missed up to 2,121 additional times that faculty published. Faculty may have published as many as 5,123 times.

In conclusion, family medicine faculty published over 3,000 times and were cited over 13,500 times. Eighty-four percent of these works were published in non-family medicine journals, underscoring the broad scope of family medicine research, and over half of the faculty publications were linked to federal funding. These figures are higher than prior estimates, are most likely underestimates of the scholarly output, and should be tracked over time.

ACKNOWLEDGMENTS: The authors thank the members of the Association of Departments of Family Medicine Research Development Committee for their input developing the methods and the FMAHealth Research Tactic Team for its support and feedback.

This analysis was presented at the 2018 Society of Teachers of Family Medicine Annual Spring Conference, May 5-9, 2018, Washington, DC.
FUNDING: This work was funded by grants from Family Medicine for America's Health and the American Board of Family Medicine Foundation.

\section{References}

1. McWhinney IR. General practice as an academic discipline. Reflections after a visit to the United States. Lancet. 1966;1(7434):419-423.

2. Fiscella K. Reflections on primary care research. Post-Starfield Summit: thinking pragmatically, thinking big. Ann Fam Med. 2016;14(4):382-383.

3. Lam CLK. The 21st century: the age of family medicine research? Ann Fam Med. 2004;2(suppl_2):S50-S54.

4. Pathman DE, Viera AJ, Newton WP. Research published in 2003 by U.S. family medicine authors. J Am Board Fam Med. 2008;21(1):6-16.

5. Dunikowski LG, Freeman TR. Impact of family medicine research: bibliometrics and beyond. Can Fam Physician. 2016;62(3):266-268.

6. Cacari-Stone L, Wallerstein N, Garcia AP, Minkler M. The promise of community-based participatory research for health equity: a conceptual model for bridging evidence with policy. Am J Public Health. 2014;104(9):1615-1623.

7. Post RE, Weese TJ, Mainous AG III, Weiss BD. Publication productivity by family medicine faculty: 1999 to 2009 . Fam Med. 2012;44(5):312-317.

8. Jelercic S, Lingard H, Spiegel W, Pichlhöfer O, Maier M. Assessment of publication output in the field of general practice and family medicine and by general practitioners and general practice institutions. Fam Pract. 2010;27(5):582-589.

9. Merenstein J, Rao G, Wolfe S, Weaver-Agostoni J. Clinical research in family medicine: published articles 2000 and 2005. Fam Med. 2009;41(1):7-8

10. Ruffin MT IV, Sheets KJ. Primary care research funding sources. J Fam Pract. 1992;35(3):281-287.

11. Web of Science. Web of Science Facts. Philadelphia: Clarivate; 2017. https://cdn.clarivate. com/wp-content/uploads/2017/05/d6b7faae3cc2-4186-8985-a6ecc8cce1ee_Crv_WoS_Upsell_Factbook_A4_FA_LR edits.pdf. Accessed January 24, 2018.

12. Falagas ME, Pitsouni EI, Malietzis GA, Pappas G. Comparison of PubMed, Scopus, Web of Science, and Google Scholar: strengths and weaknesses. FASEB J. 2008;22(2):338-342.

13. Association of American Medical Colleges. Medical School Admission Requirements. https://apps.aamc.org/msar-ui/\#/landing. Accessed January 24, 2018.

14. Liaw W, Bazemore AW, Ewigman B, et al. Advancing bibliometric assessment of research productivity: report from the Graham Center/ ADFM Study of US Departments of Family Medicine. Unpublished manuscript.

15. American Association of Colleges of Osteopathic Medicine. American Association of Colleges of Osteopathic Medicine. http://www.aacom.org/ home. Accessed January 24, 2018. 
16. Larsen PO, von Ins M. The rate of growth in scientific publication and the decline in coverage provided by Science Citation Index. Scientometrics. 2010;84(3):575-603.

17. Weaver SP. Family Medicine Academic Workforce: a national study of faculty numbers and types. Fam Med. 2015;47(2):131-133.

18. Institute of Medicine. Crossing the Quality Chasm: A New Health System for the 21st Century. Washington, DC: National Academies Press; 2001. http://www.nap.edu/catalog/10027. Accessed November 12, 2016.

19. AAFP, AAP, ACP, AOA. Patient-Centered Primary Care Collaborative. Joint Principles of the Patient-Centered Medical Home. 2007.

20. Batmangelich S, Adamowski S. Maintenance of certification in the United States: a progress report. J Contin Educ Health Prof. 2004;24(3):134-138.
21. Grumbach K, Lucey CR, Johnston SC. Transforming from centers of learning to learning health systems: the challenge for academic health centers. JAMA. 2014;311(11):1109-1110.

22. Accreditation Council for Graduate Medical Education. Family Medicine Milestone Project https://www.acgme.org/Portals/0/PDFs/Milestones/FamilyMedicineMilestones.pdf. Published October 2015. Accessed May 10, 2016.

23. Accreditation Council for Graduate Medical Education. Scholarly activity guildelines: review committee for family medicine. https:// www.acgme.org/Portals/0/PFAssets/ProgramResources/120_scholarly-activity-guidelines. pdf. Accessed November 15, 2018

24. Phillips RL Jr, Pugno PA, Saultz JW, et al Health is primary: family medicine for America's health. Ann Fam Med. 2014;12(suppl 1):S1S12.
25. Jones RF, Gold JS. The present and future of appointment, tenure, and compensation policies for medical school clinical faculty. Acad Med. 2001;76(10):993-1004.

26. Kozakowski SM, Fetter GF, Bentley A. Results of the 2015 National Resident Matching Program: family medicine-a comparison with 1997 and 2009. Fam Med. 2015;47(9):717-721. 